\title{
To evaluate alteration of salivary sodium and potassium level in hypertensive patients with and without medication
}

\author{
Mitra JK ${ }^{1}$, Mantu VK ${ }^{2}$, Mitra $\mathbf{R}^{3}$ \\ ${ }^{1}$ Dr J K Mitra, Associate professor, Department of Medicine, Rajendra Institute of Medical Sciences, Ranchi, ${ }^{2}$ Dr. \\ Vinayak Kumar Mantu, Senior Lecturer,Department of Oral Pathology and Microbiology,Vananchal Dental College and \\ Hospital, Garhwa,Jharkhand, ${ }^{3}$ Dr Ruchi Mitra, Senior Resident,Department of Dentistry, Rajendra Institute of Medical \\ Sciences, Ranchi, Jharkhand, India
}

Address for correspondence: Dr Ruchi Mitra,Senior Resident,Department of Dentistry, Rajendra Institute of Medical Sciences,Ranchi Email: dr.ruchimitra@gmail.com

\begin{abstract}
Aim: to study the alterations of sodium and potassium in saliva with change in blood pressure values and to estimate sodium and potassium level in saliva in controls and hypertensive's with the comparison and correlation of their changes. Materials and methods: 58 patients of age group between 30-70 years with 43 hypertensives and 15 controls were examined in medicine department Rajendra Institute of Medical Sciences, Ranchi for a period of about 5 weeks(one month) and unstimulated saliva was collected before and after treatment with antihypertensive drugs. Results: The hypertensive patients were characterized with significantly elevated levels of potassium ion( $\mathrm{p}=0.000)$ and less remarkable increase of sodium ion $(\mathrm{p}=0.24)$ after one month treatment as compared to controls. Also the salivary potassium ion was more marked in patients under Atenolol antihypertensive drug. Conclusions: The result may be related to the hypothesis of chronic adrenergic over stimulation of the salivary glands in hypertensive patients. Salivary concentrations of sodium and potassium ion can be used as a valuable marker and diagnostic aid in hypertensive patients.
\end{abstract}

Key word: Blood Pressure, Saliva, Hypertension, Antihypertensive, Adrenergic

\section{Introduction}

Saliva is a complex fluid secreted by salivary gland and it plays a dynamic role in oral cavity for regulating healthy environment for teeth and oral mucosa. Saliva is composed of water $(99.5 \%)$ organic $(0.3 \%)$ inorganic $\mathrm{Na}, \mathrm{K}, \mathrm{Ca}$ and inorganic trace elements $(0.2 \%)$. Trace elements include $\mathrm{Cu}, \mathrm{Pb}$, and $\mathrm{Zn}$ ions. Saliva contains both electrolytes and non-electrolytes like amino acid, proteins, carbohydrates and lipids, the concentration of $\mathrm{Na}^{+}, \mathrm{K}^{+}, \mathrm{cl}^{-}, \mathrm{HCO}_{3}{ }^{-}, \mathrm{PO}_{4}$ are the major constituents[1]. There is both parasympathetic and sympathetic nerve supply to each gland, the main effect being mediated through $\mathrm{M}_{3}-$ Muscuranic and $\mathrm{B}_{2^{-}}$adrenergic receptor respectively. The content of the primary acinar secretion is modified on its passage through the duct system. This process is also open to autonomic influences as the duct cells have parasympathetic and

Manuscript received: $1^{\text {st }}$ Oct 2015

Reviewed: $10^{\text {th }}$ Oct 2015

Author Corrected: $27^{\text {th }}$ Oct 2015

Accepted for Publication: $4^{\text {th }}$ Nov 2015 sympathetic innervations. Cholinergic stimulations reduces $\mathrm{Na}^{+}$resorption with a more variable effect on $\mathrm{K}^{+}$content [2]. Many factors influences the salivary flow rate and composition. The degree of hydration, diet and circadian rhythm are all of some importance especially with regard to flow rate $\mathrm{Na}^{+}$and $\mathrm{K}^{+}$. Effect of flow rate and duration of stimulation occurs on the $\mathrm{PCO}_{2}$ and $\mathrm{pH}[3]$.

The concentration of ions in the secretion is the result of both duct and acinar transfer process. There are many chronic systemic diseases influencing the salivary composition, hypertension is one of them. Hypertension is the silent killer of mankind. it is defined as increase in blood pressure. Exercise, anxiety, fear, emotional disturbance and unfamiliar surroundings can lead to transient elevation of blood pressure [4].

Hypertension is classified as - 
Borderline systolic Hypertension - the diastolic blood pressure is normal and systolic blood pressure is between 140 and $159 \mathrm{~mm}$ of $\mathrm{Hg}$.

Isolated systolic Hypertension- the systolic blood pressure is $160 \mathrm{~mm}$ of $\mathrm{Hg}$ and above. It influences from time to time high in the morning and low at night.

Labile hypertension- the patient is hypertensive at one time and normotensive at another time.

Accelerated hypertension- denotes a recent rise in blood pressure with complications like papilledema, retinal exudates \& hemorrhage.

The etiology of hypertension includes acute nephritis, polycystic kidney, arteriosclerosis, contraction of aorta, SLE, crushing's syndrome, thyrotoxicosis, raised intra cranial pressure \& toxiemia of pregnancy and the factors include high salt intake, smoking, glucose intolerence, obesity, alcoholism, anxiety states.The symptoms can be headache, dizziness, palpitations, fatigue, blurring of vision, angina pectoris, polyuria, polydipsia, weakness, weight gain, and emotional lability[5].

It is reported that there is decreased unstimulated whole salivary flow rate in hypertensive patient after receiving antihypertensive medications.Medications have been reported to be the reason for reduction in flow through various mechanisms[6,7]. In an epidemiological study conducted by Parvinen et al (1984), [8] it was found that medicines that caused hyposalivation were diuretics, antihypertensives and drugs for cardiovascular diseases. Therefore, saliva has been proved to be of significant clinical value. However, a limited number of studies are published on the effects of antihypertensive drugs on salivary composition mainly on sodium and potassium so far [9]. Hence, the aim of the present study is to study the alterations of sodium and potassium in saliva with change in blood pressure values and to estimate sodium and potassium level in saliva in controls and hypertensive's with the comparison and correlation of their changes.

\section{Matrial and Method}

The study was conducted in the OPD department of Medicine, RIMS, Ranchi.

Prior to the study the ethical clearance was obtained from the ethical committee and necessary corrections were done in the study design accordingly. A written informed consent was obtained from the patients participating in the study. The whole unstimulated saliva was collected by spit on method between 9 am to 10:30 am. from 58 patients (43 hypertensive and 15 controls).

The study participants included patients of age group 30-60 years and not having any other systemic diseases that causes alteration in sodium and potasium level. Patient should not take any other drugs except antihypertensive drug which will ultimately alter the sodium and potassium level.

All patients have normal function according to past medical history, patients and volunteers were selected and their clinical histories were obtained. The hypertensive patients were treated with Captopril and Atenolol (Medochema) which are considered to be the most common antihypertensive drugs used in the treatment of hypertension (in public clinics) in India many years ago especially during the years of sanctions since 1991. Blood pressure was measured and after 3 hrs, $24 \mathrm{hrs}$ and after one month, the collection of unstimulated saliva is kept at $15-25 \mathrm{C}^{\circ}$ away from direct light, on the light of this study. It seems that salivary sampling time from 9-11 AM are recommended since most of the study variables were closed to the daily mean at this time points, moreover, patients were told not to eat, drink or smoke for one hour before each sampling. Saliva was kept in centrifuge for 60 seconds at speed of 2000 r.p.m and the supernatant was isolated and transformed to another test tube which was frozen at $-4 \mathrm{C}$ [1]. Both $\mathrm{Na}$ and $\mathrm{K}$ were estimated by emission flame photometry "Corning 410" in the pathology department, RIMS, Ranchi. The samples were collected into a clean gauged test tube by spitting method.

Exclusion Criteria: Patients having any systemic disease or undergoing antibiotic therapy or any other treatments were excluded. Patients not giving consent and having adverse habits like smoking,alcohol or tobacco chewing were not included in the study due to its effect on salivary flow and composition.

Statistical Analysis: Prior to the start of the study a pilot study was conducted to determine the validity and feasibility of the study. The study was a randomized controlled single blinded with parallel study design. Data was systematically arranged and compiled and master table was prepared. Data was analysed using SPSS 19 ,and data was logically presented as tables and 
figures. The statistical tests used were mean, SD,

pearson's correlation(r), and paired t Test.

\section{Results}

A total of 60 participants were included in the study, however one patient developed bradycardia and palpitations when treated with Captopril, so the line of treatment was changed and another patient did not revert back. Both of them were excluded from the study. Therefore a total of 58 participants were included in the study with 15 controls and 43 hypertensives. In the age group of 61-70 years there were 14 hypertensive patients as compared to age group between $30-$ 40 years there were 5 hypertensives.

The systolic and diastolic variation was more in hypertensives in different age groups with more variation in older age groups. Table 1

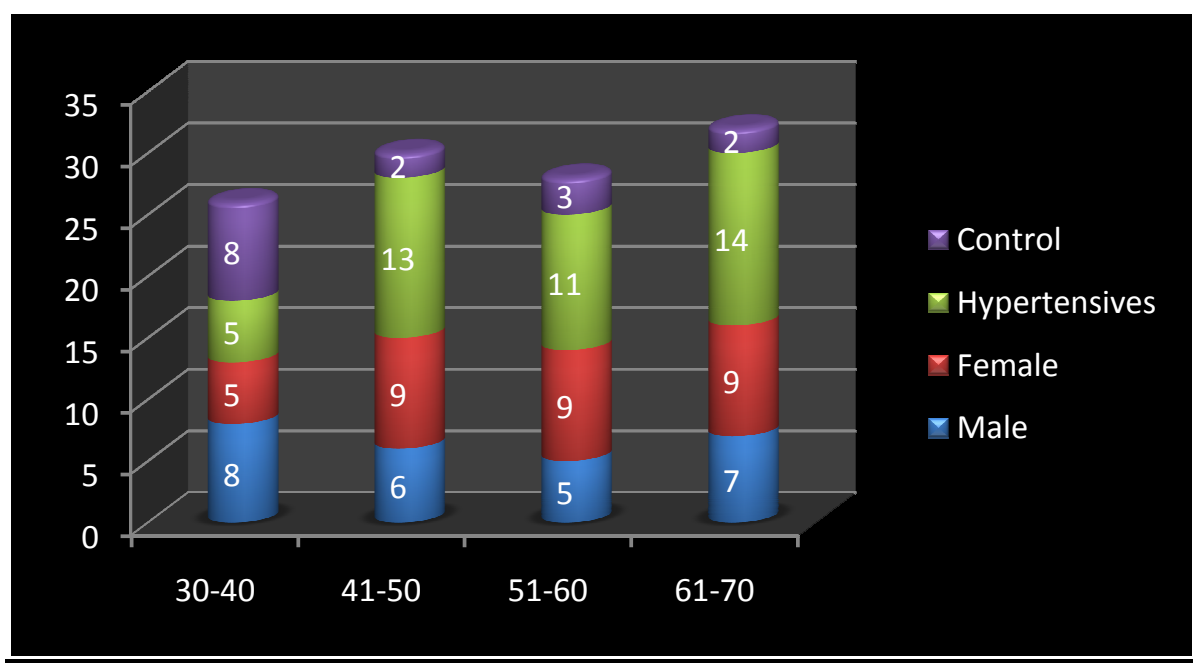

Figure 1: Distribution of the study participants(hypertensive and control group ) according to age group and gender

Table- 1: The mean values of difference in BP in hypertensive and control group before treatment

\begin{tabular}{|l|l|l|l|l|}
\hline \multirow{3}{*}{ Age Group (years) } & \multicolumn{4}{|l|}{ BP before treatment $(\mathbf{m m} / \mathbf{H g})$} \\
\cline { 2 - 5 } & Hypertensive & \multicolumn{2}{l|}{ Control } \\
\cline { 2 - 5 } & Systolic (mean \pm SD) & Diastolic (mean \pm SD) & Systolic (mean \pm SD) & Diastolic (mean \pm SD) \\
\hline $30-40$ & $142 \pm 6$ & $88 \pm 4$ & $122 \pm 10$ & $82 \pm 4$ \\
\hline $41-50$ & $150 \pm 8$ & $90 \pm 2$ & $124 \pm 2$ & $84 \pm 2$ \\
\hline $51-60$ & $148 \pm 10$ & $98 \pm 4$ & $126 \pm 4$ & $84 \pm 6$ \\
\hline $61-70$ & $152 \pm 8$ & $100 \pm 6$ & $128 \pm 6$ & $86 \pm 8$ \\
\hline
\end{tabular}

Table-3 : Variation in salivary sodium and potassium ion concentration at different intervals of Antihypertensive therapy

\begin{tabular}{|c|c|c|c|c|}
\hline Salivary components & $\begin{array}{l}\text { Control group } \\
\text { (mmol/l) } \\
(\text { Mean } \pm \text { SD) }\end{array}$ & $\begin{array}{l}\text { Treatment } \\
\text { group(hypertensive) }\end{array}$ & $\begin{array}{l}\text { Before } \\
\text { treatment } \\
(\text { mean } \pm \text { SD })\end{array}$ & $\begin{array}{l}\text { After treatment } \\
(4 \text { weeks }) \\
(\text { mean } \pm \text { SD })\end{array}$ \\
\hline \multirow[t]{2}{*}{ Sodium } & \multirow[b]{2}{*}{$7.08 \pm 1.48$} & Atenolol & $9.6 \pm 1.07$ & $5.8 \pm 0.85$ \\
\hline & & Captopril & $7.35 \pm 1.08$ & $6.5 \pm 1.23$ \\
\hline \multirow[t]{2}{*}{ Potassium } & \multirow[t]{2}{*}{$15.14 \pm 1.30$} & Atenolol & $27.9 \pm 3.9$ & $25.9 \pm 3.4$ \\
\hline & & Captopril & $17.78 \pm 4.36$ & $19.02 \pm 2.26$ \\
\hline
\end{tabular}

The salivary sodium ion in control was within normal range whereas with Atenolol and captopril there was not much variation. But, the salivary potassium ion was more in patients on Atenolol (Table 3). 
Table 4. Comparison of salivary sodium ion and potassium ion level between hypertensives(treatment group) with control (paired sample $t$ test)

\begin{tabular}{|c|c|c|c|c|c|c|c|}
\hline \multicolumn{8}{|l|}{ Salivary Sodium ION } \\
\hline Group & Mean \pm SD & $\mathbf{N}$ & SEM & t value & df & $\mathbf{r}$ & p value \\
\hline $\begin{array}{l}\text { Treatment group and control group } \\
\text { (before treatment) }\end{array}$ & $7.07 \pm 1.34$ & \multirow[t]{2}{*}{58} & 0.18 & 34.35 & 57 & 0.09 & $0.46(\mathrm{NS})$ \\
\hline $\begin{array}{l}\text { Treatment group and control group } \\
\text { (after one month) }\end{array}$ & $5.48 \pm 2.33$ & & 0.30 & 11.36 & 57 & 0.72 & $0.24(\mathrm{NS})$ \\
\hline \multicolumn{8}{|l|}{ Salivary Potassium Ion } \\
\hline Group & Mean \pm SD & $\mathbf{N}$ & SEM & t value & df & $\mathbf{r}$ & p value \\
\hline $\begin{array}{l}\text { Treatment group and control group } \\
\text { (before treatment) }\end{array}$ & $26.03 \pm 3.82$ & \multirow[t]{2}{*}{58} & 0.52 & 33.86 & 57 & 0.28 & $0.33(\mathrm{NS})$ \\
\hline $\begin{array}{l}\text { Treatment group and control group } \\
\text { (after one month) }\end{array}$ & $24.23 \pm 7.07$ & & 0.92 & 12.08 & 57 & 0.75 & $0.000(\mathrm{HS})$ \\
\hline
\end{tabular}

NS- Nonsignificant ; HS- Highly significant

The comparison between the treatment(hypertensive) and control group showed statistically no significant difference in salivary sodium ion concentration. Also there was statistically no significant difference between treatment and control group in salivary potassium ion concentration. The salivary potassium ion concentration after one month showed a statistically highly significant difference. (Table 4)

\section{Discussion}

Hypertension is a silent killer and $50 \%$ of the hypertensive patients are not getting treated as they are unaware. In our study The systolic and diastolic variation was more in hypertensives in different age groups with more variation in older age groups. This could be explained due to changing lifestyle. Other studies have reported increase blood pressure, among which the most important are age over 55 years for men, over 65 years for women which is consistent with our findings [5].

Saliva is a diagnostic tool. The understanding of the role of the salivary component in the oral cavity homeostasis is crucial to perceive how its changes or absence may be linked with pathological conditions. ${ }^{3}$ The salivary composition of the hypertensive patients differed from healthy controls. The concentrations of potassium was significantly higher $(\mathrm{p}=0.000)$ and the sodium concentration was not markedly increased $(p=0.24)$. This finding was similar to previous studies[10].

The high salivary potassium concentrations found in our study support the hypothesis that patients with essential hypertension have prolonged adrenergic overstimulation of the salivary glands. Moreover, the rise in potassium could be due to potassium output lowered by blockage of alpha-receptor. Mandel in 1989 showed that the treatment with Pindolol (another betablocker), there is no significant effect on protein and potassium due to the selectiveness of beta-blockers [3]. The same results were achieved by Musumeci and his colleagues [11] using ACE-I Angiotensin converting enzyme inhibitor as antihypertensive drug. No effect of Atenolol and Captopril was found on potassium concentration until the end of the month therefore it was not recorded. This is an ordinary result after the use of antihypertensive drugs; those with side effects were excluded from the study. Sodium appears to be less in both hypertensives groups than in the control group ( $\mathrm{p}<$ $0.05)$, similar result is obtained in the study of BenAryen in 1981[12]. However in the present study a 12 month study duration could be recommended for future studies conducted.With consideration of more drop outs and other health parameters and financial issues these limitations could not be ruled out.

\section{Conclusion}

The salivary $\mathrm{Na} / \mathrm{K}$ ratio is significantly lower in hypertensive patients. Excess dietary intake of salt causes lower $\mathrm{Na} / \mathrm{K}$ ratio in hypertensive patients this is because sodium retention with expansion of body fluid 
and sodium counterparts can suppress renin and raised blood pressure.

Therefore effect of altered salivary $\mathrm{Na} / \mathrm{K}$ ratio can induce xerostomia in patient having hypertension both with medications and without medications. Saliva acts as a diagnostic tool. The salivary sodium and potassium ion concentration can be used as a diagnostic value in hypertension. It can be used as a diagnostic aid and hypertension marker. However future studies are required to establish its significance.

\section{Funding: Nil,Conflict of interest: None. Permission of IRB: Yes}

\section{References}

1. Kaufman E, Lamster IB. The diagnostic applications of saliva--a review. Crit Rev Oral Biol Med. 2002;13(2):197-212.

2. Maier H, Coronco MT, Schindler JG, Schmirr M, Juskowa J, Heidland A.The effect of PTH on human parotid and submandibular saliva.. Oxford; Pergamon Press, 1980: 295-300.

3. Mandel ID, Zengo A, Katz R, Wotman S. Effect of adrenergic agents on salivary composition. J Dent Res. 1975 Jun;54 Spec No B:B27-33.

4. Adlin V, Channick BJ, Marks AD. Salivary sodiumpotassium ratio and plasma renin activity in hypertension. Circulation. 1969 May;39(5):685-92.

5. G. Mancia, R. Fagard, K. Narkiewicz et al. "ESH/ESC guidelines for the management of arterial hypertension: the task force for the management of arterial hypertension of the European society of hypertension (ESH) and of the European society of cardiology (ESC).Journal of Hypertension 2007;25(

9):1751-1762. Available at:

http://www.esh2013.org/wordpress/wpcontent/uploads/2013/06/ESC-ESH-Guidelines2013.pdf.

6. Närhi TO, Meurman JH, Ainamo A. Xerostomia and hyposalivation: causes, consequences and treatment in the elderly. Drugs Aging. 1999 Aug;15(2):103-16.

7. Navazesh M, Brightman VJ, Pogoda JM. Relationship of medical status, medications, and salivary flow rates in adults of different ages. Oral Surg Oral Med Oral Pathol Oral Radiol Endod. 1996 Feb;81(2):172-6.

8. Parvinen T. Stimulated salivary flow rate, $\mathrm{pH}$ and lactobacillus and yeast concentrations in persons with different types of dentition. Scand J Dent Res. 1984 Oct;92(5):412-8.

9. Ben-Aryeh H, Schiller M, Shasha S, Szargel R, Gutman D. Salivary composition in patients with essential hypertension and the effect of Pindolol. J Oral Med. 1981 Jul-Sep;36(3):76-8.

10. Rasheed RH. A comparative study between the effects of two different antihypertensive drugs on the salivary flow rate and salivary composition. J College Dentistry 2005;17(1):43-46.

11. Musumeci V, Di Salvo S, Zappacosta B, Zuppi C, Colacicco L, Cherubini P. Salivary electrolytes in treated hypertensives at low or normal sodium diet. Clin Exp Hypertens. 1993 Mar;15(2):245-56.

12. Ben-Aryeh H, Schiller M, Shasha S, Szargel $\mathrm{R}$, Gutman D. Salivary composition in patients with essential hypertension and the effect of Pindolol. J Oral Med. 1981 Jul-Sep;36(3):76-8.

\section{How to cite this article?}

Mitra JK, Mantu VK, Mitra R. To evaluate alteration of salivary sodium and potassium level in hypertensive patients with and without medication. Int J Med Res Rev 2015;3(10):1157-1161. doi: 10.17511/ijmrr.2015.i10.209. 